\title{
Characterization of AICoCrFeNi High Entropy Alloy Gas Atomized Powder
}

\author{
Pamela Karina dos Santos Bomfim ${ }^{a *}$ (1), Francisco Gil Coury ${ }^{a, b}$ (D), Pei Wang , Piter Gargarella $^{a, b, d}$ (]) \\ ${ }^{a}$ Universidade Federal de São Carlos, Programa de Pós-Graduação em Ciência e Engenharia de \\ Materiais, Rodovia Washington Luis, km 235 SP-310, 13565-905, São Carlos, SP, Brasil. \\ ${ }^{b}$ Universidade Federal de São Carlos, Departamento de Engenharia de Materiais, Rodovia Washington \\ Luís, km 235 SP-310, 13565-905, São Carlos, SP, Brasil. \\ ${ }^{c}$ Shenzhen University, College of Mechatronic and Control Engineering, Additive Manufacturing \\ Institute, Shenzhen, 518060, China. \\ ${ }^{d}$ Universidade Federal de São Carlos, Centro de Caracterização e Desenvolvimento de Materiais (CCDM), \\ Rodovia Washington Luiz, km 235, 13565-905, São Carlos, SP, Brasil.
}

Received: March 9, 2021; Revised: July 9, 2021; Accepted: October 18, 2021

\begin{abstract}
$\mathrm{AlCoCrFeNi}$ alloys are widely studied due to the combination of high strength in a wide temperature range, good corrosion and wear resistance, but they typically present low ductility. Due to this limited ductility, traditional bulk fabrication processes that involve forming are difficult, and casting processes are also non-ideal due to pronounced segregation and coarse microstructure. Therefore, both the selective laser melting and the powder metallurgy are more promising routes for this alloy, both of these use powder as starting material. This work aimed to produce powder of $\mathrm{Al}_{20} \mathrm{Co}_{20} \mathrm{Cr}_{20} \mathrm{Fe}_{20} \mathrm{Ni}_{20}$ alloy by gas atomization and to perform its detailed characterization. The results show that the powder is mainly spherical, which resulted in good flowability. Most of the powder (62\%) has a size smaller than $75 \mu \mathrm{m}$, and microscopy analyses confirmed that a B2 dendritic microstructure was formed, with A2 cuboidal precipitates.
\end{abstract}

Keywords: High entropy alloys, gas atomization, powder metallurgy.

\section{Introduction}

High entropy alloys (HEAs), also named complex concentrated alloys (CCAs), or multi-principal elements (MPEAs) and multi-component alloys, have been developed over the last decade ${ }^{1-3}$. In contrast to conventional alloys that contain one or two main solvent elements, these alloys are composed of multiple alloying elements whose concentrations typically range from 5 to 35 atomic percent $t^{4,5}$. Among HEAs systems, $\mathrm{AlCoCrFeNi}$ is one of the most popular, owing to their relatively low-cost elements, coupled with the wide range of possible mechanical properties such as high yield strength at room and elevated temperatures, good wear behavior, and excellent corrosion resistance .

Depending on their composition and processing history, their microstructure can be composed of FCC (A1) and/or BCC (A2) solid solutions together with their ordered versions $\left(\mathrm{L}_{2}\right.$ and $\mathrm{B} 2$, respectively) and in some cases also sigma phase $^{6}$. The microstructure of equiatomic $\mathrm{AlCoCrFeNi}$ is mostly composed of a B2/A2 mixture after solidification under several different reported cooling rates ${ }^{7,8}$.

Despite the aforementioned properties, the $\mathrm{AlCoCrFeNi}$ equiatomic HEA alloys exhibit poor ductility, which does not allow their processing by traditional thermomechanical

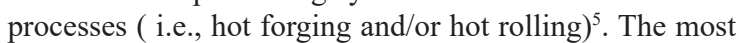
used casting processes, such as vacuum arc melting and drop-casting, apply cooling rates of around $100 \mathrm{~K} / \mathrm{s}$ or below, leading to undesirable segregation ${ }^{9}$.

*e-mail: pamelasbomfim@ppgcem.ufscar.br
In this context, some conventional consolidation methods of Powder Metallurgy, such as powder extrusion, spark plasma sintering (SPS) and hot isostatic pressing (HIP), are favorable alternatives to obtain bulk HEA material ${ }^{10}$. Indeed, there are multiple literature reports of HEA powders produced by mechanical alloying (MA) followed by conventional consolidation processes, resulting in better properties than as-cast materials. Nevertheless, during the MA process, the powders may be contaminated by the milling medium and the environment, affecting the mechanical properties ${ }^{11}$.

Hence, powders produced either by gas atomization $(\mathrm{GA})^{12}$ or by plasma spheroidization ${ }^{13}$, if on the correct particle size and morphology, are perhaps even more suitable routes to produce such powders. The gas atomization is more common comparing these two methods and presents higher powder productivity. It is a rapid solidification process that involves the disintegration of a stream of liquid metal into droplets of different sizes through a jet of inert gas ${ }^{14-16}$. Many variables control the production of powders via GA, such as overheating temperature, gas composition, gas pressure, and GMR ratio, i.e., the ratio of gas mass flow rate $(\mathrm{G})$ to metal mass flow rate (M), but the last two are the most important processing parameters ${ }^{17}$. Typically, increasing gas pressure reduces the median particle size $\left(\mathrm{D}_{50}\right)$ due to increased gas velocity for a given nozzle. In other words, the particles' size reduces as the relative velocity between the droplets and gas rises ${ }^{18}$. A high GMR ratio results in a high velocity of the atomized droplets, which in turn generates 
high heat losses by convection to the atomization gas and also very high cooling rates $\left(10^{3}-10^{5} \mathrm{~K} / \mathrm{s}\right)$, yielding a refined microstructure, metastable phases, and little segregation ${ }^{15}$. This is an important advantage since some HEAs might require very long homogenization times, such as 20-60 hours at high temperatures ${ }^{11}$.

The available studies on equiatomic $\mathrm{AlCoCrFeNi}$ powders are focused on: i) the effect of heat treatment on the microstructural evolution and the mechanical properties of $\mathrm{AlCoCrFeNi}$ powder ${ }^{19}$; ii) analysis of the microstructural evolution and mechanical and corrosion behavior of AlCoCrFeNi alloy produced by spark plasma sintering ${ }^{20}$, and iii) characterization of $\mathrm{AlCoCrFeNi}$ atomized and annealed powders for plasma spray coatings ${ }^{21}$.

However, a detailed investigation of physical characteristics and microstructural evolution of $\mathrm{AlCoCrFeNi}$ powder under strictly controlled processing parameters has not been reported so far. Moreover, the phase formation in these rapidly solidified powders is also not well clarified yet either, and careful and in-depth microscopy analyses are necessary to evaluate the formation of B2, L12, A1, and/or A2 phases under these specific solidification conditions.

Thus, this paper's noteworthy contribution was producing $\mathrm{AlCoCrFeNi}$ powders by gas atomization, ensuring their appropriate characteristics and detailed microstructural evolution for conventional consolidation processes.

\section{Materials and Methods}

$\mathrm{AlCoCrFeNi}$ ingots were prepared from elements with purity above $99.5 \%$ using an induction furnace Inductotherm 50-30R. After, these ingots were atomized in a PSI - HERMIGA under a gas atomization pressure of $60 \mathrm{bar}$, nozzle diameter of $2.5 \mathrm{~mm}$, gas-metal ratio of $5.9 \mathrm{~m}^{3} / \mathrm{Kg}$, and an atomization temperature of $1487^{\circ} \mathrm{C}$, which was around $100^{\circ} \mathrm{C}$ above the alloys liquidus temperature. These parameters were established in order to obtain spherical and fine powders. When the atomization process was completed, the powders were cooled down to room temperature in an argon atmosphere. In order to characterize the resulting powders, they were sieved into seven particle size ranges: greater than 180 , 106-180, 75-106, 53-75, 32-53, 20-32 $\mu \mathrm{m}$, and below $20 \mu \mathrm{m}$. Also, the flowability behavior was measured using Hall Funnel according to ASTM B213 Standard. The average value and standard deviation were calculated based on seven measurements. The true powder density was obtained with AccuPyc II 1330 gas displacement pycnometry system, using the process described at ASTM B 293 standard. To ensure measurement accuracy, five measurements were carried out.

Microstructural characterization was carried out by X-ray diffraction (XRD) using Rigaku Geiger-Flex X-ray diffractometer with $\mathrm{Cu}-\mathrm{Ka}$ radiation $(0,15406 \mathrm{~nm})$. Scanning and transmission electron microscopy (SEM and TEM) analysis were also carried out using, respectively, a Philip XL-30 FEG SEM, operating at $30 \mathrm{kV}$ or below, and an FEI Talos F200X TEM, operating at 200kV. Both microscopes are coupled with energy-dispersive X-ray spectroscopy (EDX) system for chemical analysis.

The TEM samples were prepared by argon ion milling in a Gatan Precision Ion Polishing System (PIPS). Only splats of powders with a size greater than 180 microns were analyzed because it was not possible to prepare good-quality samples of powder with smaller particle sizes.

To investigate the microstructure of atomized $\mathrm{AlCoCrFeNi}$ powders, the cross-sections were prepared using standard metallographic procedure finishing with alumina $1 \mu \mathrm{m}$ polishing. The polished samples were etched with aqua regia (1:3 vol mixture of nitric acid and hydrochloric acid) for 3 minutes.

\section{Results and Discussion}

The powder's chemical composition by EDX/SEM is presented in Table 1, showing that the elements' uniform distribution is close to its nominal equiatomic composition. Figure 1 displays the particle size distribution by both mass and accumulated mass percentages. About $62 \%$ of the particles had a diameter smaller than $75 \mu \mathrm{m}$, and the mean mass diameter $\left(D_{50}\right)$ is $63 \mu \mathrm{m}$.

SEM micrographs of the atomized powders in the range of $20-180 \mu \mathrm{m}$ are shown in Figure 2. Distinct morphologies are seen among different granulometric ranges. Smaller powders present more spherical morphology due to the higher cooling rate, which is inversely proportional to the powder size, in agreement with the observation of Mazzer et al. ${ }^{18}$. The spherical shape leads to better flowability and packing density. On the other hand, larger powder sizes usually have more irregular morphologies and more satellite particles, which may compromise the Hall Flow rate ${ }^{12,13}$. The flowability of powders in the range $20-75 \mu \mathrm{m}$ showed a good flow behavior $(19.3 \pm 0.3 \mathrm{~s} / 50 \mathrm{~g})$ compared to commonly used alloys Ti-6Al-4V, IN718, and AlSi10Mg: 32.4, 28.3, and $62.0 \mathrm{~s} / 50 \mathrm{~g}$, respectively. The density of the atomized powder

Table 1 . Nominal and measured chemical composition (\% at.) of the $\mathrm{AlCoCrFeNi}$ (EDS/SEM).

\begin{tabular}{ccc}
\hline Elements & Nominal & Measured \\
\hline $\mathbf{A l}$ & 20 & $17.9 \pm 1.3$ \\
\hline $\mathbf{C o}$ & 20 & $22.5 \pm 1.8$ \\
\hline $\mathbf{C r}$ & 20 & $19.7 \pm 2.4$ \\
\hline $\mathbf{F e}$ & 20 & $20.4 \pm 0.6$ \\
\hline $\mathbf{N i}$ & 20 & $19.4 \pm 0.0$ \\
\hline
\end{tabular}

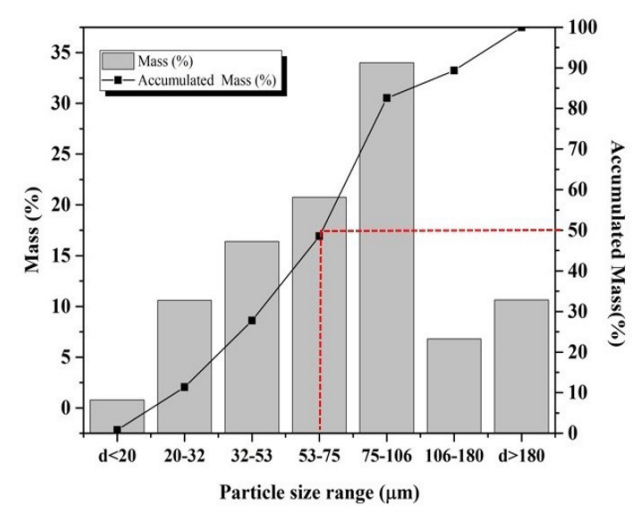

Figure 1. Mass and cumulative percent for different particle size ranges of the $\mathrm{AlCoCrFeNi}$ powder. 

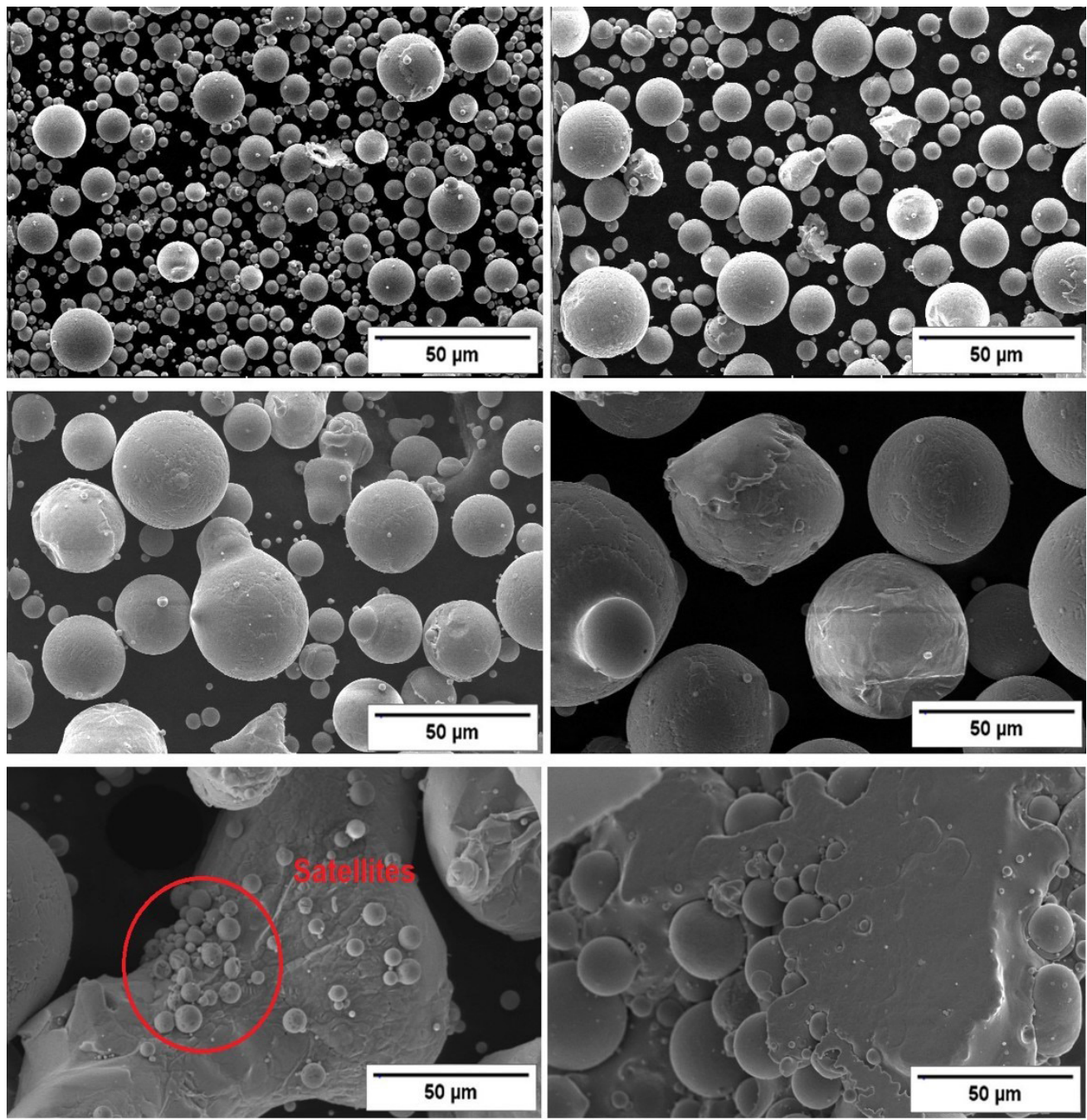

Figure 2. Secondary electron (SE) images showing the spherical and irregular morphology of the powders.

was $7.11 \pm 0.01 \mathrm{~g} / \mathrm{cm}^{3}$, which is below the theoretical value $\left(8.0 \mathrm{~g} / \mathrm{cm}^{3}\right)^{22}$.

Although the XRD pattern result (Figures 3a, b) exhibit pronounced peaks of the A2 phase, there are (100) and (111) weak reflections of the B2 phase in accordance with the literature ${ }^{19,23}$. For example, Cheng et al. ${ }^{23}$ stated that their powders $\left(\mathrm{Al}_{20.6} \mathrm{Co}_{20.1} \mathrm{Cr}_{20.4} \mathrm{Fe}_{19.4} \mathrm{Ni}_{19.4}\right)$ consisted of a major amount of A2 phase and also B2 phase in a minor amount with the characteristic reflection (100).

It is known that A2 and B2 phases formed together may have similar lattice parameter, especially on this alloy, in which both these phases are formed by a multi-step decomposition from a high-temperature A2 phase into two nanometric phases: another A2 phase enriched $\mathrm{Fe}-\mathrm{Cr}$ plus an Al-Co-Ni rich B27,9 . The B2 superlattice reflections are not very intense, given the relative proximity of this system's elements in the periodic table, which yields a small structure factor for these extra reflections. Therefore, it is necessary to perform the further investigation by TEM to confirm the presence, morphology, and fraction of the A2 and B2 phases $^{24}$.
As shown by the dark field image (DF), the microstructure of the splat is composed of fine precipitates of 22 phase into B2 matrix (Figure 4a). The selected area electron diffraction

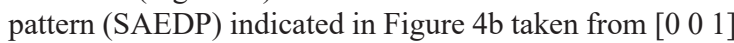
zone axis confirmed the presence of the two phases ${ }^{7-9,24}$.

Although TEM analysis was performed on the splats produced at a cooling rate of $10^{2} \mathrm{~K} / \mathrm{s}$ slightly lower when compared to $10^{5}-10^{4}$ for $20-120$ powders size range ${ }^{17,25}$, it is still a high value. This allowed noting the presence of A2rich precipitates and bands into the B2 matrix (Figure 4a). In addition, the A2/B2 phases can be seen in XRD pattern in all particle ranges (Figures $3 \mathrm{a}, \mathrm{b}$ ). Therefore, given the similarity of the final microstructure (Figure $4 a$ ) and its pattern diffraction (Figure $4 b$ ), which enabled us to consider the solid-state transformation path for such alloy which is described as follows. According to recent Monte Carlo simulations ${ }^{7}$ at high temperatures (above $800^{\circ} \mathrm{C}$ ), the equiatomic $\mathrm{AlCoCrFeNi}$ alloy most likely presents only the A2 phase. At approximately $800^{\circ} \mathrm{C}$, the alloy transforms into a partially B2 ordered phase. Upon further cooling, the partially ordered phase (B2) transforms into a mixture of 
a)

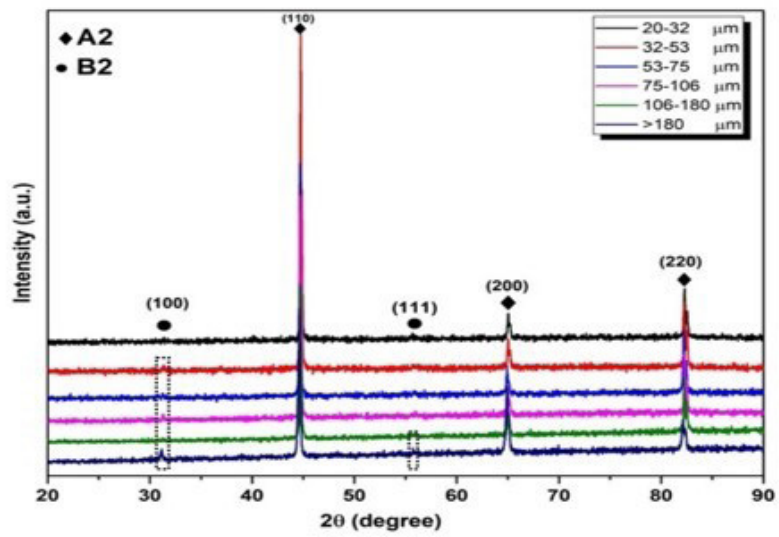

b)

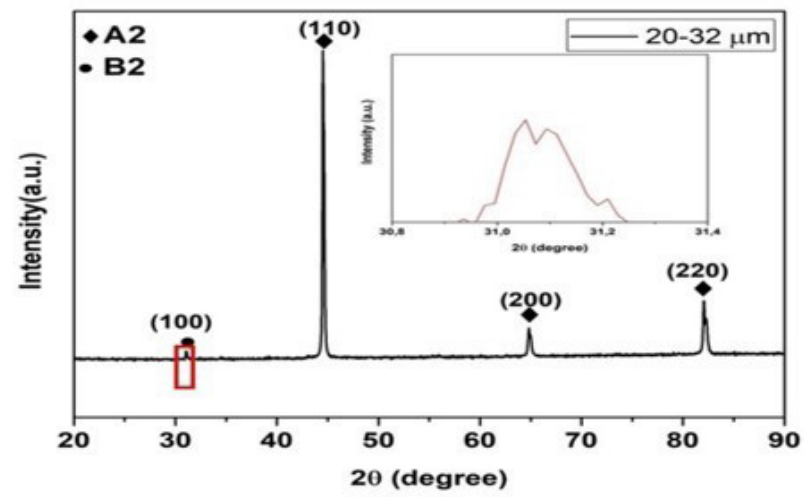

Figure 3. (a) XRD results of AlCoCrFeNi powders with different particle sizes. The weak (100) and (111) superlattice peaks at $31.1^{\circ}$ and $55.9^{\circ}$, respectively, marked with circles, indicate the presence of the B2 phase; (b) XDR detailed for 20-32 $\mu \mathrm{m}$ particle sizes using longer scan time.

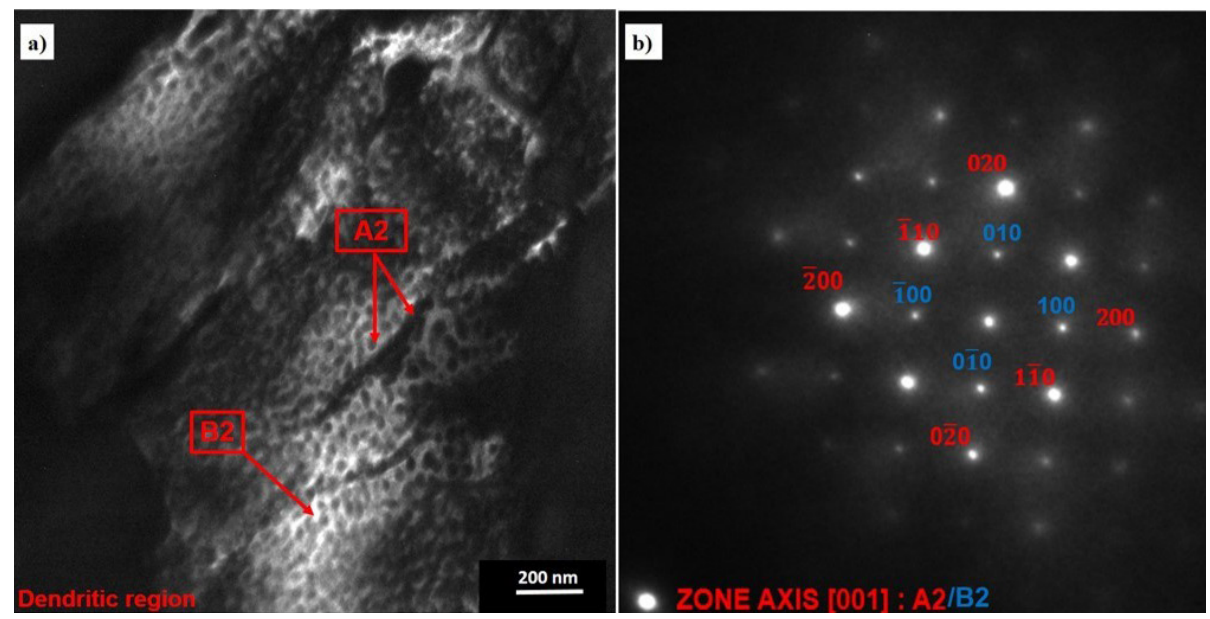

Figure 4. TEM analysis of the dendritic region of the $\mathrm{AlCoCrFeNi}$ : (a) Dark Field (DF) image obtained from a splat (particles with size larger than $180 \mu \mathrm{m}$ ) using the 100 reflection from B2 under two-beam condition; (b) SAEDP of the A2 and B2 structure taken from zone axis [001].

another disordered $\mathrm{Cr}-\mathrm{Fe}$ enriched $\mathrm{A} 2$ and ordered $\mathrm{AlCoNi}$ enriched $\mathrm{B} 2$ phases by short atomic motions. This phenomenon can be explained by the dominant role of aluminum, which has a very negative bonding energy with the other elements in this alloy, explaining the first B2 ordering followed by decomposition into another a with nickel and cobalt-rich B2 phase. This configuration is energetically favored at lower temperatures since it promotes a larger number of pairs of $\mathrm{Co} / \mathrm{Ni}$ and $\mathrm{Al}$ demonstrated by the very negative interaction energies calculated $(-7.58$ and $-8.15 \mathrm{KJ} / \mathrm{mol}$, respectively), in 
a)
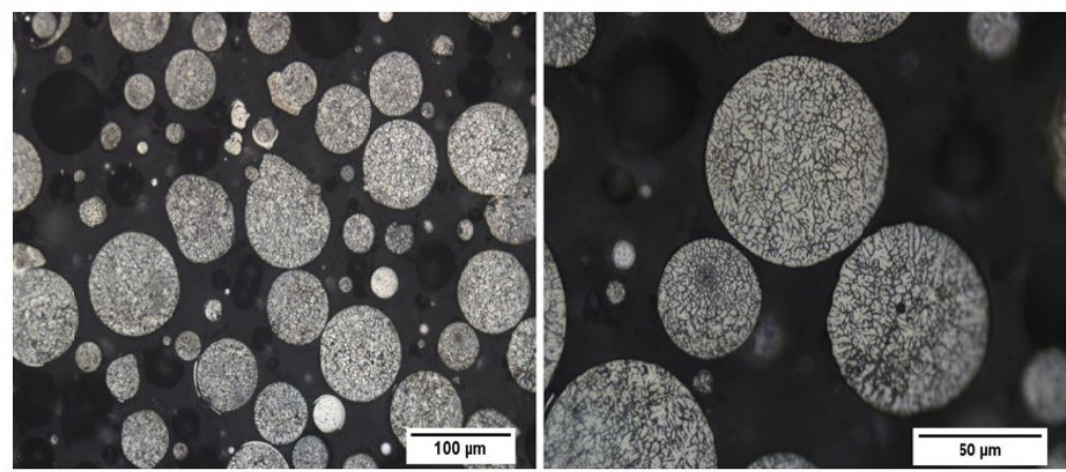

b)

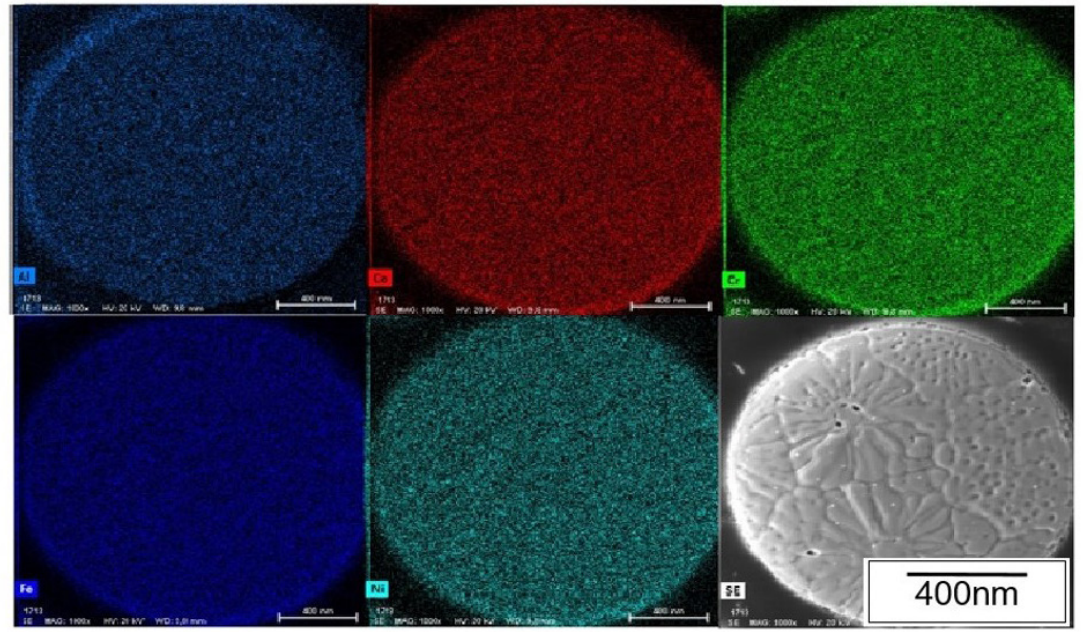

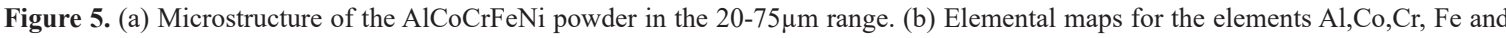
Ni by EDX/ SEM.

contrast to the lower interaction energies between other pairs such as $\mathrm{Co}-\mathrm{Cr}, \mathrm{Co}-\mathrm{Fe}, \mathrm{Co}-\mathrm{Ni}, \mathrm{Cr}-\mathrm{Fe}, \mathrm{Cr}-\mathrm{Ni}$ and $\mathrm{Fe}-\mathrm{Ni}(0.06$; $0.72 ;-0.25 ;-0.10 ;-0.36$ and $-0.07 \mathrm{KJ} / \mathrm{mol}$, respectively) $)^{7}$. This is further evidenced by a higher Al-containing material, the $\mathrm{Al}_{33} \mathrm{Co}_{16.7} \mathrm{Cr}_{16.7} \mathrm{Fe}_{16.7} \mathrm{Ni}_{16.7}$ alloy, which does not exhibit the A2 phase at all since the ordering temperature (Tc) would be higher than the liquidus temperature ${ }^{7}$.

Based on this, it is clear that such decomposition's kinetics are very fast, and increasing the cooling rate during solidification would not change the final morphology since this is a pure solid-state transformation. However, it is expected that smaller particles would also experience a higher cooling rate in the solid-state compared to bigger particles like splats. In this case, considering the experimental evidence displayed in Figure 3 where we clearly see the presence of the same phases for all powder size ranges, the A2/B2 domains are expected to be increasingly more refined for finer particle sizes, which frequently occurs in the similar systems ${ }^{25}$.

In short, the order-disorder transition cannot be observed experimentally step by step. Therefore, we suggest this decomposition kinetics as the most plausible explanation for the resultant morphology.

It can be seen in Figure 5a the microstructure of the powder in the range of $20-75 \mu \mathrm{m}$ with secondary dendrite arm spacings of about $1.8 \mu \mathrm{m}, 3.9 \mu \mathrm{m}, 5.4 \mu \mathrm{m}$, and $7.0 \mu \mathrm{m}$ for the particle size of $20 \mu \mathrm{m}, 32 \mu \mathrm{m}, 53 \mu \mathrm{m}$, and $75 \mu \mathrm{m}$, respectively. This result highlights the close relationship between secondary dendritic arm spacings and the cooling rates/ size powders as mentioned in the literature ${ }^{17}$.

Although it is expected to observe more segregation with increasing powder size, a relatively homogeneous elemental distribution was found in the different powders sizes, with no evidence of chemical segregation within the EDX mapping detection limits (Figure 5b). It should be highlighted that the same alloy produced by arc melting, which involves much slower cooling rates, the chemical segregation was also small, as reported by Ferrari et al. ${ }^{24}$.

In short, the gas atomization process was a promising route in producing spherical particles with the homogeneous chemical composition of the equiatomic $\mathrm{AlCoCrFeNi}$ alloy powder, and it will probably be to other alloys with high aluminum content.

\section{Conclusions}

In this work, $\mathrm{AlCoCrFeNi}$ powder was produced by gas atomization. The physical properties of the powder and its resulting microstructure were analysed. From the results, the following conclusions were drawn:

- $\quad \mathrm{AlCoCrFeNi}$ powder was successfully produced through inert gas atomization, with $62 \%$ of the powder smaller than $75 \mu \mathrm{m}$. 
- $\quad$ Gas atomized powders below $75 \mu \mathrm{m}$ were mostly spherical and show a small number of satellite particles, with $63 \mu \mathrm{m}$ of mean diameter and high flowability.

- The XRD and TEM analyses indicated the formation of dendrites composed of an A2/B2 nanometric mixture and the secondary dendrite arm spacings were $1.8 \mu \mathrm{m}, 3.9 \mu \mathrm{m}, 5.4 \mu \mathrm{m}$ and $7.0 \mu \mathrm{m}$ for particle sizes $20 \mu \mathrm{m}, 32 \mu \mathrm{m}, 53 \mu \mathrm{m}$ and $75 \mu \mathrm{m}$, respectively.

- These results show that the powder obtained presents adequate properties for powder metallurgy processes.

\section{Acknowledgments}

The authors would like to thank the Brazilian research funding agencies - This study was financed in part by the Coordenação de Aperfeiçoamento de Pessoal de Nivel Superior- Brasil (CAPES)- Finance code 001, São Paulo Foundation Research - FAPESP (Grant 2017/27031-4) and National Council of Technological and Scientific Development - Brazil / CNPQ (Grant 167845/2018-7). Additionally, the Laboratory of Structural Characterization of Department of Materials Engineering at the Federal University of São Carlos (LCE/DEMa/UFSCar) for the microscopy facilities.

\section{References}

1. Coury FG. Solid solution strengthening mechanisms in high entropy alloys [thesis]. Golden: Faculty and the Board of Trustees of the Colorado School of Mines; 2018 [cited 2021 Mar 9]. Available from: https://hdl.handle.net/11124/172516.

2. Tang Z, Senkov ON, Parish CM, Zhang C, Zhang F, Santodonato LJ, et al. Tensile ductility of an AlCoCrFeNi multi-phase high-entropy alloy through hot isostatic pressing (HIP) and homogenization. Mater Sci Eng A. 2015;647:229-40.

3. Coury FG, Wilson P, Clarke KD, Kaufman MJ, Clarke AJ. High-throughput solid solution strengthening characterization in high entropy alloys. Acta Mater. 2019;167:1-11.

4. Fujieda T, Shiratori H, Kuwabara K, Kato T, Yamanaka K, Koizumi Y, et al. First demonstration of promising selective electron beam melting method for utilizing high-entropy alloys as engineering materials. Mater Lett. 2015;159:12-5.

5. Shiratori H, Fujieda T, Yamanaka K, Koizumi Y, Kuwabara $\mathrm{K}$, Kato T, et al. Relationship between the microstructure and mechanical properties of an equiatomic $\mathrm{AlCoCrFeNi}$ highentropy alloy fabricated by selective electron beam melting. Mater Sci Eng A. 2016;656:39-46.

6. Zhang C, Zhang F, Diao H, Gao MC, Tang Z, Poplawskyd $\mathrm{JD}$, et al. Understanding phase stability of Al-Co-Cr-Fe-Ni high entropy alloys. Mater Des. 2016;109:425-33.

7. Santodonato LJ, Liaw PK, Unocic RR, Bei H, Morris JR. Predictive multiphase evolution in Al-containing high-entropy alloys. Nat Commun. 2018;9:1-10.

8. Meshi L, Linden Y, Munitz A, Salhov S, Pinkas M. Retardation of the $\sigma$ phase formation in the $\mathrm{AlCoCrFeNi}$ multi-component alloy. Mater Charact. 2019;148:171-7.

9. Karlsson D, Marshal A, Johansson F, Schuisky M, Sahlberg M, Schneider JM, et al. Elemental segregation in an $\mathrm{AlCoCrFeNi}$ high-entropy alloy - a comparison between selective laser melting and induction melting. J Alloys Compd. 2019;784:195-203.

10. Torralba JM, Alvaredo P, García-Junceda A. High-entropy alloys fabricated via powder metallurgy. A critical review. Powder Metall. 2019;62:84-114.

11. Liu B, Wang J, Liu Y, Fang Q, Wu Y, Chen S, et al. Microstructure and mechanical properties of equimolar FeCoCrNi high entropy alloy prepared via powder extrusion. Intermetallics. 2016;75:25-30.

12. Aboulkhair N, Maskery I, Ashcroft I, Tuck C, Everitt N. The role of powder properties on the processability of Aluminium alloys in selective laser melting. In: Lasers in Manufacturing Conference 2015; Munique. Munique: German Scientific Laser Society; 2015. p. 1-12.

13. Park JM, Kang JW, Lee WH, Lee SY, Min S, Ha TK, et al. Preparation of spherical WTaMoNbV refractory high entropy alloy powder by inductively-coupled thermal plasma. Mater Lett. 2019;255:126513.

14. Dietrich S, Wunderer M, Huissel A, Zaeh MF. A new approach for a flexible powder production for additive manufacturing. Procedia Manufacturing. 2016;6:88-95.

15. Cava RD, Bolfarini C, Kiminami CS, Mazzer EM, Botta WJ Fo, Gargarella P, et al. Spray forming of Cu-11.85Al-3.2Ni-3Mn (wt\%) shape memory alloy. J Alloys Compd. 2015;615:S602-6.

16. Ferrarini CF, Bereta LA, Botta WJ Fo, Kiminami CS, Bolfarini C. Microstructural characterization of rapidly solidified Al$6.5 \% \mathrm{Si}-4 \% \mathrm{Cu}$ alloy powders produced by gas atomization. $\mathrm{J}$ Metastable Nanocryst Mater. 2005;24-25:519-22.

17. Zheng B, Lin Y, Zhou Y, Lavernia EJ. Gas atomization of amorphous aluminum powder: part II. experimental investigation. Metall Mater Trans, B, Process Metall Mater Proc Sci. 2009;40:995-1004.

18. Mazzer EM, Kiminami CS, Gargarella P, Cava RD, Basilio LA, Bolfarini C, et al. Atomization and selective laser melting of a Cu-Al-Ni-Mn shape memory alloy. Mater Sci Forum. 2014;802:343-8.

19. Liang JT, Cheng KC, Chen SH. Effect of heat treatment on the phase evolution and mechanical properties of atomized AlCoCrFeNi high-entropy alloy powders. J Alloys Compd. 2019;803:484-90.

20. Zhou PF, Xiao DH, Yuan TC. Microstructure, Mechanical and Corrosion Properties of AlCoCrFeNi high-entropy alloy prepared by spark plasma sintering. Acta Metall Engl Lett. 2020;33:937-46.

21. Zhou S, Zhang P, Xue Y, Wang F, Wang L, Cao T, et al. Microstructure evolution of A10.6CoCrFeNi high entropy alloy powder prepared by high pressure gas atomization. T Nonferr Metal Soc. 2018; 28(5):939-45.

22. Mohanty S, Maity TN, Mukhopadhyay S, Sarkar S, Gurao NP, Bhowmick S, et al. Powder metallurgical processing of equiatomic $\mathrm{AlCoCrFeNi}$ high entropy alloy: microstructure and mechanical properties. Mater Sci Eng A. 2017;679:299-313.

23. Cheng KC, Chen JH, Stadler S, Chen S-H. Properties of atomized $\mathrm{AlCoCrFeNi}$ high-entropy alloy powders and their phase-adjustable coatings prepared via plasma spray process. Appl Surf Sci. 2019;478:478-86.

24. Ferrari V, Wolf W, Zepon G, Coury FG, Kaufman MJ, Bolfarini $\mathrm{C}$, et al. Effect of boron addition on the solidification sequence and microstructure of AlCoCrFeNi alloys. J Alloys Compd. 2019;775:1235-43.

25. Grant NJ. Rapid solidification of metallic particulates. J Miner Met Mater Soc. 1983;35:20-7. 